\title{
Review of Literature on Post-traumatic Epilepsy in Extradural Hematoma Patients: A Case for Further Comprehensive Research
}

\author{
Adesh Shrivastava ${ }^{1} \quad$ Md Moshiur Rahman², ${ }^{2} \quad$ Luis Rafael Moscote-Salazar ${ }^{3,4} \quad$ Rajeev Ravish Keni ${ }^{5}$ \\ Manas Prakash ${ }^{1} \quad$ Amit Agrawal $^{1}$
}

${ }^{1}$ Department of Neurosurgery, All India Institute of Medical

Sciences, Saket Nagar, Bhopal, Madhya Pradesh, India

${ }^{2}$ Department of Neurosurgery, Holy Family Red Crescent Medical

College, Dhaka, Bangladesh

${ }^{3}$ Department of Neurosurgery, Paracelsus Medical University,

Salzburg, Austria

${ }^{4}$ Department of Neurosurgery, Universidad de Cartagena,

Cartagena, Colombia

${ }^{5}$ Department of Neurology, Narayana Medical College and Hospital, Nellore, Andhra Pradesh, India

Indian J Neurotrauma:2021;18:95-96

The early and aggressive management of extradural hematomas (EDH) is a classical teaching during neurosurgery residency. ${ }^{1-3}$ Posttraumatic seizures (PTS) after EDH share a significant percentage of causality, but apparently remain a less studied entity. The major literature analyzing EDH with PTS dates back to the late 20th century and there are only a couple of recent studies.-7 Additionally, an often-debated issue is the role of prophylactic antiepileptic drugs (AEDs) in patients suspected of having high chances of developing PTS. ${ }^{8,9}$ Uniform use of AEDs in all cases can lead to drug-related side effects and complications and in some cases unnecessary AED dependence., ${ }^{9,10}$

An online search PubMed database was performed by using literature and using the search strategy "((("extradural haematoma"[All Fields] OR "hematoma, epidural, cranial"[MeSH Terms] OR ("hematoma"[All Fields] AND "epidural"[All Fields] AND “cranial"[All Fields]) OR “cranial epidural hematoma"[All Fields] OR ("extradural"[All Fields]AND "hematoma"[All Fields]) OR "extradural hematoma"[All Fields]) AND ("epilepsy"[MeSH Terms] OR "epilepsy"[All Fields])) AND ("seizures"[MeSH Terms] OR "seizures"[All Fields])) AND (“anticonvulsants"[All Fields] OR "anticonvulsants"[MeSH Terms] OR "anticonvulsants"[All Fields])" on PTS after EDH returned only a handful of articles ( - Fig. 1) $)^{4,5,7}$ Three studies were excluded as there was no clear categorization of intracranial hematomas, ${ }^{11}$ diagnosis of extradural hematoma not clearly mentioned, ${ }^{12}$ and no clear description of seizure groups. ${ }^{13}$

One of the early reports was by Bryan Jennett from the Institute of Neurological Sciences, Glasgow in $1975 .{ }^{5}$ The peculiarity of this report was that the case series was of
Address for correspondence Adesh Shrivastava, MCh, Department of Neurosurgery, All India Institute of Medical Sciences, Saket Nagar, Bhopal 462020, Madhya Pradesh, India

(e-mail: dr.adesh.shrivastava@gmail.com).

the pre-CT era and surgical interventions were based only on clinical findings. Among patients of seizures due to posttraumatic intracranial hematomas (excluding chronic subdural hematomas), EDH was reported as a cause of early seizures (within 1 week of head injury)in 10\%(15/146) and late seizures in $22 \%$ (13/59) patients. Jennet also found out that only $2 \%$ of early PTS patients had an evolving EDH. The next significant report came in 1991 by Jamjoom et al from Bristol. ${ }^{4}$ They categorized EDH patients with epilepsy in two subgroups, based on CT findings into those with exclusive EDH and those with other intradural traumatic insults. ${ }^{4}$ Although they found the overall incidence of late epilepsy to be $6 \%$, in the pure EDH group, it was only $2 \%$ as against $17 \%$ of those with additional intradural damage. Another data analysis from a multicentre North American TBI database of 795 patients from 1989 to 2000 was reported by Ritter et al in 2016. ${ }^{7}$ Among the various findings, EDH was found to be the cause of early and late PTS in $14.5 \%$ and $16.9 \%$, respectively. The most recent report on the incidence of PTS due to EDH came from the series of 484 TBI patients by Pormontree et al from Thailand in 2019. ${ }^{6}$ The authors analyzed early PTS in TBI patients from April 2017 to March 2018. Twenty-seven patients (5.6\%) had early PTS due to various intracranial insults. Among these, EDH was found to have an adjusted odds ratio of 3.98 on multivariate analysis ( $p$ value $=0.001$ ).

PTS is a known complication of head injury. $6.7,10,14-17$ Whether they occur in the early (within a week) or in late posttraumatic period, this sequela of brain injury can significantly deteriorate the quality of life and is considered an independent factor., ${ }^{6,74-17}$ All the contemporary studies on published online

October 9, 2020
DOI https://doi.org/

$10.1055 / \mathrm{s}-0040-1718243$

ISSN 2277-954X. (c)2020. Neurotrauma Society of India.

This is an open access article published by Thieme under the terms of the Creative Commons Attribution-NonDerivative-NonCommercial-License, permitting copying and reproduction so long as the original work is given appropriate credit. Contents may not be used for commercial purposes, or adapted, remixed, transformed or built upon. (https://creativecommons.org/licenses/by-nc-nd/4.0/).

Thieme Medical and Scientific Publishers Pvt. Ltd. A-12, 2nd Floor, Sector 2, Noida-201301 UP, India 


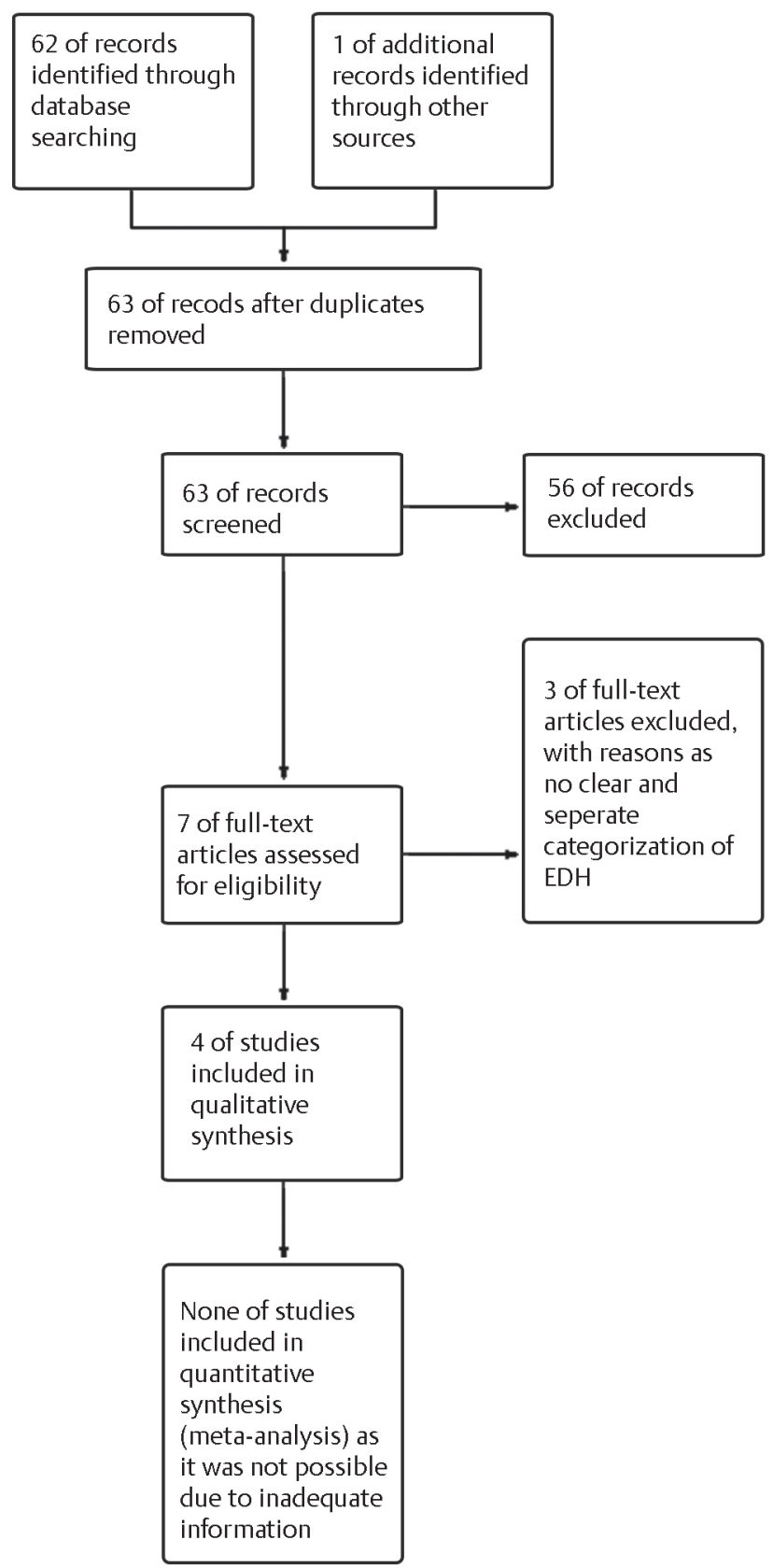

Fig. 1 Prisma chart of the studies extracted using keyword-based PubMed search.

posttraumatic epilepsy (PTE) are in patients with intradural injuries. ${ }^{10,16,18}$ Hence, considering the significant share of PTE attributed to EDH in the tune of 15 to $20 \%$, there is an emergent need to undertake a well-formulated study to understand the exact correlation in the current advanced imaging era and then accordingly tailor the prophylactic antiepileptic treatment.

\section{Conflict of Interest}

None declared.

\section{References}

1 Khairat A, Waseem M, Epidural Hematoma. StatPearls. Treasure Island (FL): StatPearls Publishing; 2020

2 Paiva WS, Andrade AF, Mathias Júnior L, et al. Management of supratentorial epidural hematoma in children: report on 49 patients. Arq Neuropsiquiatr 2010;68(6):888-892

3 Rosenthal AA, Solomon RJ, Eyerly-Webb SA, et al. Traumatic epidural hematoma: patient characteristics and management. Am Surg 2017;83(11):e438-e440

4 Jamjoom AB, Kane N, Sandeman D, Cummins B. Epilepsy related to traumatic extradural haematomas. BMJ 1991;302(6774):448

5 Jennett B. Epilepsy and acute traumatic intracranial haematoma. J Neurol Neurosurg Psychiatry 1975;38(4):378-381

6 Parmontree P, Tunthanathip T, Doungngern T, Rojpitbulstit M, Kulviwat W, Ratanalert S. Predictive risk factors for early seizures in traumatic brain injury. J Neurosci Rural Pract 2019;10(4):582-587

7 Ritter AC, Wagner AK, Fabio A, et al. Incidence and risk factors of posttraumatic seizures following traumatic brain injury: a traumatic brain injury model systems study. Epilepsia 2016;57(12):1968-1977

8 Temkin NR, Dikmen SS, Anderson GD, et al. Valproate therapy for prevention of posttraumatic seizures: a randomized trial. J Neurosurg 1999;91(4):593-600

9 Temkin NR, Dikmen SS, Wilensky AJ, Keihm J, Chabal S, Winn HR. A randomized, double-blind study of phenytoin for the prevention of post-traumatic seizures. N Engl J Med 1990;323(8):497-502

10 Agrawal A, Timothy J, Pandit L, Manju M. Post-traumatic epilepsy: an overview. Clin Neurol Neurosurg 2006;108(5):433-439

11 Younus SM, Basar S, Gauri SA, et al. Comparison of phenytoin versus levetiracetam in early seizure prophylaxis after traumatic brain injury, at a tertiary care hospital in Karachi, Pakistan. Asian J Neurosurg 2018;13(4):1096-1100

12 Phillips G. Traumatic epilepsy after closed head injury. J Neurol Neurosurg Psychiatry 1954;17(1):1-10

13 Sherman WD, Apuzzo MLJ, Heiden JS, Petersons VT, Weiss MH. Gunshot wounds to the brain-a civilian experience. West J Med 1980;132(2):99-105

14 Annegers JF, Hauser WA, Coan SP, Rocca WA. A populationbased study of seizures after traumatic brain injuries. N Engl J Med 1998;338(1):20-24

15 Fernández-Abinader JA, González-Colón K, Feliciano CE, Mosquera-Soler AM. Traumatic brain injury profile of an elderly population in Puerto Rico. P R Health Sci J 2017;36(4):237-239

16 Salazar AM, Jabbari B, Vance SC, Grafman J, Amin D, Dillon JD. Epilepsy after penetrating head injury. I. Clinical correlates: a report of the Vietnam Head Injury Study. Neurology 1985;35(10):1406-1414

17 Temkin NR. Risk factors for posttraumatic seizures in adults. Epilepsia 2003;44(s10):18-20

18 Jennett B. Epilepsy after non-missile head injuries. Scott Med J 1973;18(1):8-13 